\title{
Relationship between Smokeless Tobacco Dependence and Psychiatric Disorders
}

\author{
Vijayraj $\mathbf{N}^{1}$ \\ ${ }^{1}$ Assistant Professor, Department of Psychiatry, Vijayanagara Institute of Medical Sciences, Ballari, Karnataka.
}

\section{Abstract}

Background: The epidemiology of nicotine dependence indicates how strongly addictive a drug it is that nearly half of those who ever smoked steadily for a month become highly nicotine dependent. It is a psychoactive substance that induces euphoria, reinforces its own use, and leads to nicotine withdrawal syndrome when it is absent. Subjects and Methods: Written informed consent was taken from all the cases and controls prior to the detailed assessment. The personal data was recorded in the socio demographic data. They were administrated Modified Fagerstrom test for nicotine dependence [FTND] and those who were nicotine dependent were then screened for psychiatric morbidity using GHQ - 12 [69] screening questionnaire. Results: Among those with psychiatric diagnosis majority had Major Depressive Disorder [24\%], Generalized Anxiety disorder [18\%], Mixed Anxiety Depressive disorder [10\%] and Alcohol dependence syndrome[14\%] as compared to nonnicotine dependents. Conclusion: Severity of Anxiety and depression increased with the severity of nicotine dependence among the cases.Coping skills were not significantly different between cases and controls.

Keywords: Smokeless tobacco dependence, Psychiatric disorders, Modified Fagerstrom test for nicotine dependence.

Corresponding Author: Dr. Vijayraj N, Assistant Professor, Department of Psychiatry, Vijayanagara Institute of Medical Sciences, Ballari, Karnataka.

Received: October 2019

Accepted: October 2019

\section{Introduction}

Tobacco use appears as old as human civilization. It was introduced in to India by Portuguese traders during 1600 A.D. as valuable commodity of barter trade. Its production proliferated as it was used as a commodity for export during British rule. Its use and production proliferated to such a great extent that today India is second largest producer of tobacco in the world. ${ }^{[1]}$

Properties like stimulation, pleasure, reducing stress, anxiety, improvement in attention, concentration, ability, to suppress hunger and its easy assimilation into cultural rituals facilitated the tobacco use. As its use increased health hazards due to tobacco started appearing ranging from peptic ulcer, asthma, Ischemic Heart Disease, cerebrovascular accidents, pulmonary Tuberculosis, Myocardial Infarction, Hypertension and arteriosclerosis. It has adverse effects on pregnancy outcomes, spontaneous abortion, infertility, ectopic pregnancy, low birth weight, preterm labor and placenta previa. To cancers of lip mouth, pharynx, larynx, lung, esophagus, liver kidney and cervix, proving the saying "Too much is too bad." $[2,3,4]$ this result in preventable human suffering and the loss of many years of productive life.

Tobacco is the also single most preventable causes of death in the world today. In $20^{\text {th }}$ century tobacco killed about one hundred million people worldwide. By 2030 the death toll will exceed eight million a year and could kill one billion people during this century. ${ }^{[6]}$

The epidemiology of nicotine dependence indicates how strongly addictive a drug it is that nearly half of those who ever smoked steadily for a month become highly nicotine dependent. It is a psychoactive substance that induces euphoria, reinforces its own use, and leads to nicotine withdrawal syndrome when it is absent. ${ }^{[7]}$ smoking and smokeless tobacco use are initiated and established primarily during adolescence. More than $80 \%$ of adults smokers begin smoking before 18 years of age. ${ }^{[8]}$ The highest risk for nicotine dependence occurred in the first sixteen years after daily smoking began, at which point the rate declines and continued at a slower pace of several years. Greater involvement with any one substance increased the risk of other substance use. ${ }^{[9]}$

Smokeless tobacco use has become highly prevalent in India in recent years due to commercially available preparations. ${ }^{[10]}$ over $34.6 \%$ of Indians use tobacco in any form of which $25.9 \%$ used smokeless tobacco, $14.0 \%$ used smoked tobacco of which $5.7 \%$ were cigarette smokers and $9.2 \%$ were beedi smokers. ${ }^{[5]}$

Many previous studies have shown a significant association of tobacco use and psychiatric disorders mainly Depression, ${ }^{[11,}{ }^{12]}$ Anxietyy ${ }^{[13]}$ substance use disorder, ${ }^{[8,9]}$ Schizophrenia ${ }^{[14]}$ and other psychiatric disorders. ${ }^{[15]}$ the use and withdrawal of nicotine can also be associated with depression and anxiety symptoms. It seems likely that substance misuse can activate new psychiatric disorders and 
aggravate the current disorders. Patients with psychiatric problems and substance abuse are much more likely to remain dependent and less successful at abstinence attempts. The issue of co morbidity of substance use disorders and psychiatric disorders and has become a major policy issue.

Tobacco addiction, like other addiction, is a complex process involving the interplay of pharmacology, conditioned factors, personality, coping strategies and social setting. Thus people with difficulty in coping skills have an increased propensity for tobacco use and hence increased psychiatric morbidity. Therefore, a comprehensive approach that addresses all major co morbidities of tobacco addiction should be dealt to prevent the psychiatric morbidity and reduce substance use disorders.

Despite scientific evidence that smokeless tobacco use is widespread and is highly addictive, little information is available about the prevalence of smokeless tobacco use and relationship to psychiatric morbidity. ${ }^{[9]}$ most studies of psychiatric comorbidity done in nicotine use disorders are in smokers and western context. Hence the present study was planned to assess the psychiatry morbidity among smokeless tobacco users.

\section{Subjects and Methods}

\section{Types of Study}

The entire study is a cross - sectional, hospital based, case control study.

\section{Source of Data}

Sample for the current study was drawn from patients attending OPD at Medical College.Controls were also patients attending medical college who were non-nicotine dependent and were visiting the dental college for other dental treatments.

\section{Inclusion Criterion}

1. Patients using tobacco currently in chewable form.

2. Both male and female sexes between $18-60$ years were included.

3. Patients who consented for detailed psychiatric assessment.

\section{Exclusion Criterion}

1. Patients who have smoked tobacco presently or in the past two months were excluded from study.
2. Patients who use Nicogum were excluded from study.

3. Patients having psychiatric illness prior to nicotine use.

4. Mental retardation, head injury cases were excluded.

The control group formed people who were not using tobacco in any form and attending the same dental OPD.

\section{Method of Interview}

Written informed consent was taken from all the cases and controls prior to the detailed assessment. The personal data was recorded in the socio demographic data. They were administrated Modified Fagerstrom test for nicotine dependence [FTND] and those who were nicotine dependent were then screened for psychiatric morbidity using GHQ 12 [69] screening questionnaire. Those who scored positive for one item were subjected to MINI plus [70] for assessment of axis -1 disorders. The severity of depression and anxiety was assessed using Hamilton Depression Rating Scale [72] and Hamilton anxiety Rating Scale [73] respectively. Finally their coping strategies were assessed using copy checklist.[74] similarly controls were also assessed but Modified FTND was not used and controls were non nicotine dependents. Details were also confirmed with a relative/ accompanying person.

\section{Statistical Analysis}

Analysis was done using SPSS 21 IBM version of software. To compare between groups test was done for continuous variables. For categorical variables chi-square test was used. Statistical significance was set at 0.005 levels.

\section{Results}

A total of 72 cases admitted to our hospital between Jan 2017 to Dec 2018 were statically analyzed. Most of the dengue cases presented during the month of August and September which depicts the role of rainy season for case clustering during that season.

\begin{tabular}{|c|c|c|c|c|}
\hline & Negative & 19 & 45 & $\mathrm{X}^{2}=29.34, \mathrm{df}=1, \mathrm{P}<0.000$ \\
\hline \multicolumn{2}{|c|}{ Hamilton Depression Rating Scale(mean\&sd) } & $8.94 \pm 7.47$ & $3.02 \pm 2.91$ & \multirow{3}{*}{$\begin{array}{l}\mathrm{l}=5.22, \mathrm{df}=98, \mathrm{P}<0.000 \\
\mathrm{X}^{2}=24.35, \mathrm{df}=3, \mathrm{P}<0.000\end{array}$} \\
\hline \multirow[t]{2}{*}{ HDRS categories } & Normal & 25 & 47 & \\
\hline & Mild & 9 & 1 & \\
\hline $\begin{array}{l}\text { Hamilton Anxiety Rating } \\
\text { Scale(mean\&sd) }\end{array}$ & & $\begin{array}{l}12.16 \pm \\
9.00\end{array}$ & $\begin{array}{l}5.62 \pm \\
4.98\end{array}$ & $\begin{array}{l}\mathrm{t}=4.49, \mathrm{df}=98, \\
\mathrm{P}<0.000\end{array}$ \\
\hline \multirow[t]{4}{*}{ HARS categories } & Normal & 23 & 47 & \multirow[t]{4}{*}{$\mathrm{X}^{2}=28.49, \mathrm{DF}=3, \mathrm{P}<0.000$} \\
\hline & Mild & 14 & 1 & \\
\hline & Moderate & 6 & 2 & \\
\hline & Severe & 7 & 0 & \\
\hline
\end{tabular}


Table 2: Comparison of socio demographic data with severity of nicotine dependence $[\mathrm{N}=50]$ in cases

\begin{tabular}{|c|c|c|c|c|}
\hline \multirow{2}{*}{\multicolumn{2}{|c|}{$\begin{array}{l}\text { Socio demographic variables \&Fagerstrom Test } \\
\text { for Nicotine Dependence in cases }\end{array}$}} & \multicolumn{2}{|l|}{ Cases $[\mathrm{N}=50]$} & \multirow[b]{2}{*}{ Statistical analysis } \\
\hline & & $\begin{array}{l}\text { Low to mod dependence } \\
{[N=16]}\end{array}$ & $\begin{array}{l}\text { Moderate to high dependence } \\
{[\mathrm{N}=34]}\end{array}$ & \\
\hline \multicolumn{2}{|l|}{ Age [mean \&sd ] } & $41.94 \pm 10.0$ & $40.12 \pm 12.35$ & $\mathrm{t}=0.51, \mathrm{NS}$ \\
\hline \multirow[t]{2}{*}{ Age categories } & Less than 30 & 2 & 12 & $\mathrm{x}^{2}=2.80, \mathrm{df}=1, \mathrm{NS}$ \\
\hline & More than 30 & 14 & 22 & \\
\hline \multirow[t]{2}{*}{ Sex } & Male & 5 & 31 & \multirow[t]{2}{*}{$\mathrm{x}^{2}=19.38, \mathrm{df}=1 \mathrm{p}<0.04$} \\
\hline & Female & 11 & 3 & \\
\hline \multirow[t]{2}{*}{ Place } & Rural & 4 & 17 & \multirow[t]{2}{*}{$\mathrm{x}^{2}=4.17 \mathrm{df}=1, \mathrm{p}<0.04$} \\
\hline & Urban & 12 & 17 & \\
\hline \multirow[t]{3}{*}{ Religion } & Hindu & 15 & 27 & \multirow[t]{2}{*}{$x^{2}=1.66, d f=1, N S$} \\
\hline & Muslim & 1 & 7 & \\
\hline & Nil & 6 & 6 & \\
\hline \multirow[t]{5}{*}{ Education } & Upto 9th & 4 & 8 & \\
\hline & SSLC & 1 & 9 & \multirow[t]{4}{*}{$\mathrm{x}^{2}=2.4, \mathrm{df}=5 \mathrm{NS}$} \\
\hline & PUC & 4 & 3 & \\
\hline & Diploma & 0 & 4 & \\
\hline & Degree & 1 & 4 & \\
\hline \multirow[t]{3}{*}{ Occupation } & Housewife & 6 & 1 & \multirow[t]{3}{*}{$\mathrm{X}^{2}=14.24, \mathrm{df}=5 \mathrm{p}<0.01$} \\
\hline & Agriculture & 1 & 7 & \\
\hline & Business & 1 & 7 & \\
\hline \multirow[t]{2}{*}{ Marital status } & Married & 13 & 20 & \multirow[t]{2}{*}{$\mathrm{x}^{2}=2.43 \mathrm{df}=1, \mathrm{NS}$} \\
\hline & Unmarried & 3 & 14 & \\
\hline \multirow[t]{2}{*}{ Types of family } & Joint & 5 & 11 & \multirow{2}{*}{$\begin{array}{l}\mathrm{x}^{2}=0.0061, \mathrm{df}=1, \\
\mathrm{NS}\end{array}$} \\
\hline & Nuclear & 11 & 23 & \\
\hline \multirow[t]{3}{*}{ Socio economic status } & High & 5 & 8 & \multirow[t]{3}{*}{$\mathrm{x}^{2}=0.338, \mathrm{df}=2, \mathrm{NS}$} \\
\hline & Middle & 6 & 14 & \\
\hline & Low & 5 & 12 & \\
\hline
\end{tabular}

Table - 3 Comparison of socio demographic data with severity of nicotine dependence in psychiatrically positive cases

Socio demographic variables \&Fagerstrom Test for Nicotine Dependence in Cases

\begin{tabular}{|c|c|}
\hline \multicolumn{2}{|l|}{ Age [mean \&sd] } \\
\hline \multirow{2}{*}{ Age categories } & Less than 30 \\
\hline & More than 30 \\
\hline \multirow[t]{2}{*}{ Sex } & Male \\
\hline & Female \\
\hline \multirow[t]{2}{*}{ Place } & Rural \\
\hline & Urban \\
\hline \multirow[t]{3}{*}{ Religion } & Hindu \\
\hline & Muslim \\
\hline & Nil \\
\hline \multirow[t]{5}{*}{ Education } & Upto 9th \\
\hline & SSLC \\
\hline & PUC \\
\hline & Diploma \\
\hline & Degree \\
\hline \multirow[t]{6}{*}{ Occupation } & Agriculture \\
\hline & Business \\
\hline & Employed-Govt \\
\hline & Student \\
\hline & Coolie \\
\hline & Housewife \\
\hline \multirow[t]{2}{*}{ Marital status } & Married \\
\hline & Unmarried \\
\hline \multirow[t]{2}{*}{ Type of family } & Joint \\
\hline & Nuclear \\
\hline \multirow[t]{3}{*}{ Socio Economic status } & High \\
\hline & Middle \\
\hline & Low \\
\hline
\end{tabular}

\section{Psychiatrically positive $\mathrm{N}=\mathbf{3 4}$}

\section{Low to mod dependence Moderate to High}

[N = 11]

$46.09 \pm 8.26$

0

\begin{tabular}{l|l}
0 & 5 \\
\hline 11 & 18 \\
\hline
\end{tabular}

\begin{tabular}{|l|l}
\hline 4 & 20 \\
\hline 7 & 3
\end{tabular}

\begin{tabular}{|l|l}
\hline 7 & 3 \\
\hline 2 & 13 \\
\hline
\end{tabular}

\begin{tabular}{l|l}
\hline & \\
\hline
\end{tabular}

\begin{tabular}{|l|l}
\hline & 13 \\
\hline 11 & 20 \\
\hline
\end{tabular}

\begin{tabular}{|l|l}
11 & 3 \\
\hline 5 & 6 \\
\hline 3
\end{tabular}

\begin{tabular}{l|l}
5 \\
\hline
\end{tabular}

\begin{tabular}{l|l}
-2 & \\
\hline & \\
\hline
\end{tabular}

\begin{tabular}{|l|l}
\hline & 6 \\
\hline & 2 \\
\hline
\end{tabular}

\begin{tabular}{l|l}
\hline \\
\hline
\end{tabular}

\begin{tabular}{l|l}
\hline & 2 \\
\hline & 6
\end{tabular}

\begin{tabular}{l|l}
\hline & \\
\hline
\end{tabular}

\begin{tabular}{|l|l|}
\hline & 7 \\
\hline & 1 \\
\hline
\end{tabular}

\begin{tabular}{lll}
\hline & 1 \\
\hline &
\end{tabular}

\begin{tabular}{l|l}
\hline & 7 \\
\hline
\end{tabular}

\begin{tabular}{|l|l}
4 & \\
\hline 11 &
\end{tabular}

\begin{tabular}{|l|l}
\hline 11 & 18 \\
\hline
\end{tabular}

\begin{tabular}{l|l}
11 & 5 \\
\hline 2 & 6 \\
\hline
\end{tabular}

\begin{tabular}{|c|c|c|}
\hline 0 & 5 & $\mathrm{x}^{2}=2.803, \mathrm{df}=1, \mathrm{NS}$ \\
\hline 2 & 6 & \multirow[b]{2}{*}{$\mathrm{x}^{2}=0.25, \mathrm{df}=1 \mathrm{NS}$} \\
\hline 9 & 17 & \\
\hline 4 & 7 & \multirow[b]{3}{*}{$\mathrm{x}^{2}=1.56, \mathrm{df}=2, \mathrm{NS}$} \\
\hline 5 & 7 & \\
\hline 2 & 9 & \\
\hline
\end{tabular}

Table 4: Comparison of Clinical variables with Gender among cases.

\section{Clinical variables}

FTND mean and Sd

FTND

Low and moderate dependence Moderate to high dependence

Hamilton depression rating scale(mean and $\mathrm{Sd}$ )

\begin{tabular}{l|l} 
HDRS Categories & normal \\
\hline
\end{tabular}

\begin{tabular}{|l|l|l|l|}
\hline \multicolumn{2}{|c|}{ Cases $\mathbf{N}=\mathbf{5 0}$} & \multirow{2}{*}{ Statistical analysis } \\
\cline { 1 - 2 } & Male $\mathbf{N}=\mathbf{3 6}$ & Female $\mathbf{N}=\mathbf{1 4}$ & \\
\hline $6.22 \pm 1.86$ & $3.28 \pm 1.38$ & $\mathrm{t}=5.32, \mathrm{p}<0.000$ \\
\hline 5 & 11 & $\mathrm{X}^{2}=22.72, \mathrm{df}=1, \mathrm{p}<0.000$ \\
\hline 31 & 3 & \\
\hline $11.5 \pm 9.28$ & $12.85 \pm 9.86$ & $\mathrm{t}=0.45, \mathrm{NS}$ \\
\hline 19 & 6 & $\mathrm{X}^{2}=4.27$, \\
\hline
\end{tabular}


Vijayraj : Relatianship letween Smakeless Salacca Dependence and Psychiatric Disarders

\begin{tabular}{|c|c|c|c|c|}
\hline & mild & 4 & 5 & \multirow{3}{*}{$\begin{array}{l}\mathrm{Df}=3, \\
\mathrm{NS}\end{array}$} \\
\hline & moderate & 9 & 2 & \\
\hline & severe & 4 & 1 & \\
\hline \multicolumn{2}{|c|}{ hamiltons anxiety rating scales } & $8.89 \pm 8.24$ & $8.0 \pm 6.75$ & $\mathrm{t}=0.36, \mathrm{NS}$ \\
\hline \multirow[t]{4}{*}{ HARS categories } & Normal & 16 & 7 & \multirow{4}{*}{$\begin{array}{l}X^{2}=0.45 \\
D f=3, \\
N S\end{array}$} \\
\hline & Mild & 11 & 3 & \\
\hline & Moderate & 4 & 2 & \\
\hline & severe & 5 & 2 & \\
\hline \multirow{7}{*}{$\begin{array}{l}\text { Coping style } \\
\text { questionnaire }\end{array}$} & Problem solving & $6.83 \pm 1.79$ & $7.71 \pm 1.54$ & $\mathrm{t}=1.6, \mathrm{NS}$ \\
\hline & Distraction positive & $7.72 \pm 2.83$ & $7.71 \pm 2.86$ & $\mathrm{t}=0.009, \mathrm{NS}$ \\
\hline & Distraction negative & $2.0 \pm 1.69$ & $1.5 \pm 1.34$ & $\mathrm{t}=0.99, \mathrm{NS}$ \\
\hline & Acceptance/redefinition & $7.11 \pm 1.78$ & $7.28 \pm 1.48$ & $\mathrm{t}=0.32, \mathrm{NS}$ \\
\hline & Faith/religion & $2.86 \pm 2.21$ & $3.07 \pm 2.49$ & $\mathrm{t}=0.29, \mathrm{NS}$ \\
\hline & Blame/denial & $3.94 \pm 2.4$ & $4.5 \pm 1.01$ & $\mathrm{t}=0.01, \mathrm{NS}$ \\
\hline & Social support & $3.92 \pm 1.20$ & $4.5 \pm 1.01$ & $\mathrm{t}=1.60, \mathrm{NS}$ \\
\hline \multirow[t]{2}{*}{ Diagnosis } & Present & 24 & 10 & \multirow{2}{*}{$\begin{array}{l}X^{2}=0.105, \\
P=0.745, N S\end{array}$} \\
\hline & absent & 12 & 4 & \\
\hline
\end{tabular}

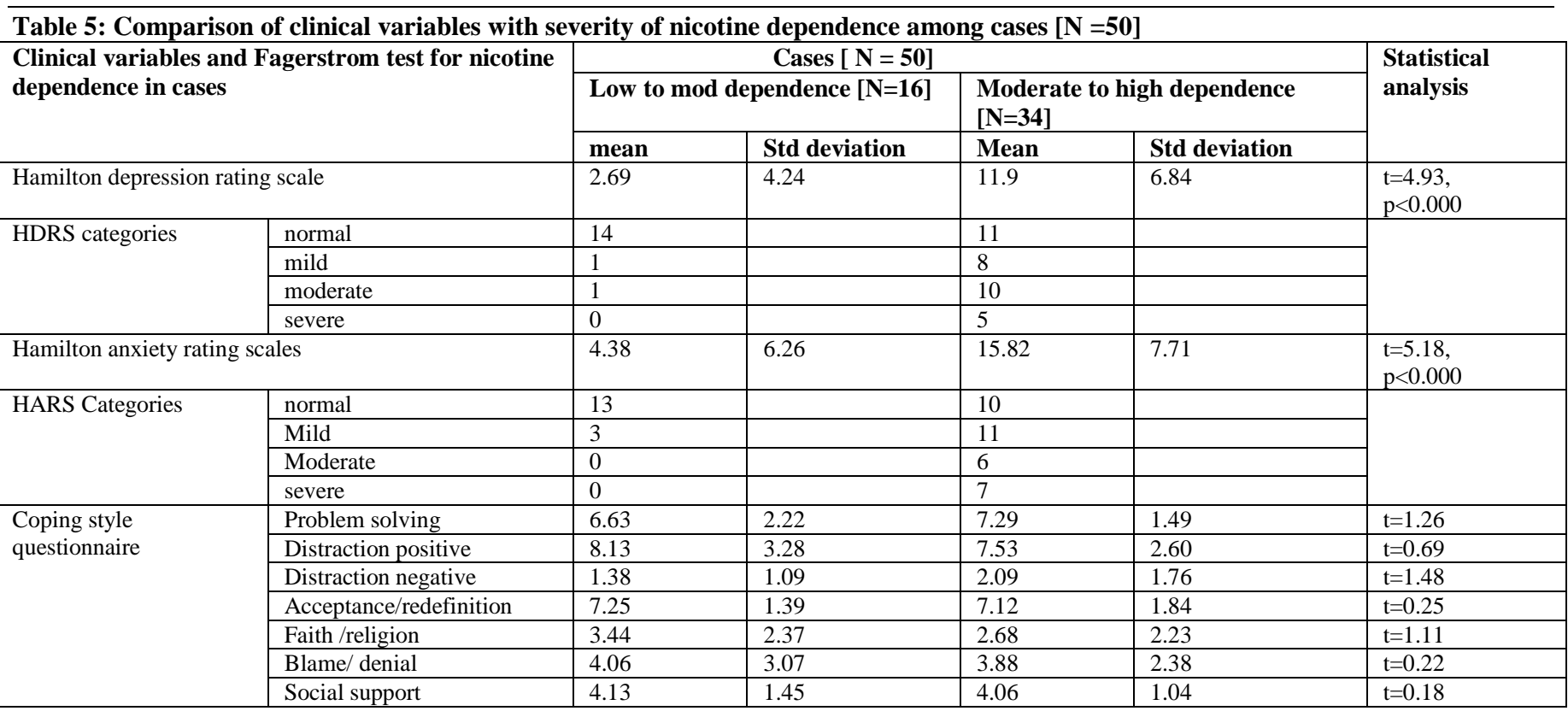

Table 6: Comparison of clinical variable with severity of nicotine dependence in psychiatrically cases positive cases [N=34]

\begin{tabular}{|c|c|c|c|c|}
\hline \multirow{2}{*}{\multicolumn{2}{|c|}{$\begin{array}{l}\text { Clinical variables \& Fagerstrom Test for Nicotine Dependence in } \\
\text { cases }\end{array}$}} & \multicolumn{3}{|c|}{ Psychiatrically positive $N=34$} \\
\hline & & $\begin{array}{l}\text { Low to } \\
\text { moddependenceN = } \\
11\end{array}$ & $\begin{array}{l}\text { Moderate to high } \\
\text { dependence }[N=23]\end{array}$ & $\begin{array}{l}\text { Statistical analysis } \\
\text { test } \mathbf{d f}=32\end{array}$ \\
\hline \multicolumn{2}{|c|}{ Hamilton Depression Rating scale [mean \&sd] } & $10.4 \pm 5.39$ & $12.56 \pm 7.45$ & 0.84 \\
\hline \multirow{4}{*}{ HDRS } & Normal & 4 & 7 & \multirow{4}{*}{ NS } \\
\hline & Mild & 3 & 5 & \\
\hline & Moderate & 3 & 7 & \\
\hline & Severe & 1 & 4 & \\
\hline \multicolumn{2}{|c|}{ Hamilton anxiety Rating scale[mean\&sd] } & $17.91 \pm 4.76$ & $14.8 \pm 8.7$ & 1.14 \\
\hline \multirow{4}{*}{ HARS categories } & Normal & 2 & 8 & \multirow{4}{*}{$\begin{array}{l}\mathrm{x}^{2}=3.45 \\
\mathrm{df}=3, \mathrm{NS}\end{array}$} \\
\hline & Mild & 5 & 6 & \\
\hline & Moderate & 3 & 3 & \\
\hline & Severe & 1 & 6 & \\
\hline \multirow{6}{*}{$\begin{array}{l}\text { Coping style } \\
\text { questionnaire }\end{array}$} & Problem solving & $7.36 \pm 1.68$ & $7.26 \pm 2.42$ & 0.18 \\
\hline & Distraction positive & $6.64 \pm 2.84$ & $7.95 \pm 2.42$ & 1.47 \\
\hline & Acceptance/Redefinition & $1.64 \pm 1.5$ & $2.3 \pm 1.87$ & 1.03 \\
\hline & Faith/Religion & $2.36 \pm 2.01$ & $2.83 \pm 2.35$ & 0.56 \\
\hline & Blame/Denial & $3.18 \pm 2.56$ & $4.21 \pm 2.27$ & 1.19 \\
\hline & Social support & $4.18 \pm 1.07$ & $4.0 \pm 1.04$ & 0.47 \\
\hline
\end{tabular}

GHQ: 31 of the 50 cases and 5 of the 50 controls had psychiatric morbidity.

The difference was statistically significant.

MINI PLUS: 34 of the 50 cases and 5 of the 50 controls had psychiatric diagnosis on MINI PLUS. This difference was also statistically significant.

Hamilton Depression Rating Scale [HDRS] : The mean score \&standard deviation of cases was $8.94 \pm 7.47$ and among controls was $3.02 \pm 2.91$. This difference was statistically significant.

Hamilton Anxiety Rating Scale [HARS] : The mean score 
\&standard deviation of cases was $12.16 \pm 9.00$ and among controls was 5.62 \pm 4.98. This difference was statistically significant.

The above table shows comparison of socio demographic data with severity of nicotine dependence. Nicotine Dependent Cases were divided into two groups for comparison as Low to Moderate [scores 1- 4] and moderate to High [5 \& above] based on FTND scores. Moderate TO High dependence was more frequently present in males and from rural background. This was statistically significant. Cases with occupation of Agriculture, Business and Coolie also had significantly higher frequency of Moderate to High dependence. However other socio demographic characteristics did not predict the severity of dependence.

The above table shows comparison of socio demographic data with severity of nicotine dependence in psychiatrically positive cases. Cases with moderate to high dependence were more commonly males and more than 30 years old. This was statistically significant. Other socio demographic characteristic did not predict the severity of dependence.

The mean score and standard deviation on FTND for males was $6.22 \pm 1.86$ and female was $3.28 \pm 1.38$. This difference was statistically significant. $[\mathrm{P}<0.000]$ Majority of nicotine dependents were male of moderate to high nicotine dependents $[\mathrm{P}<0.000]$ as compared to females. Males had significantly higher scores on FTND and had moderate to High dependence. Males also had a psychiatric diagnosis more frequently. However there was no gender difference on HARS,HDRS, Coping check list.

The above table shows comparison of clinical variables with severity of nicotine dependence among cases.

The mean and standard deviation on HDRS for low to moderate nicotine dependents \& moderate to high dependents was $2.69 \pm 4.24 \& 11.9 \pm 6.84$ respectively. Those with moderate to high nicotine dependents had higher scores on HDRS and this difference was statistically significant. $[\mathrm{P}<0.000]$

The mean and standard deviation on HARS for low to moderate nicotine dependents \& moderate to high dependence was $4.38 \pm 6.29 \& 15.82 \pm 7.71$ respectively. Those with moderate to high nicotine dependents also had higher scores on HARS and this difference was statistically significant. $[\mathrm{P}<0.000]$

However there was no significant correlation of coping checklist subscale with severity on nicotine dependence.

The above table shows comparison of clinical variables with severity of nicotine dependents in psychiatrically positive cases.

No significant difference was found between the two groups.

\section{Discussion}

There is consistent finding that substance use disorders and other psychiatric disorders are strongly correlated. It seems likely that substance use can activate new psychiatric disorders and aggravate the current disorders and a bidirectional ${ }^{[16]}$ relationship exists between substance use disorder and psychiatric disorders. A causative effect is not clear in relation to nicotine use; however it is likely that people with pre-existing psychiatric disorder are more likely to use nicotine. Earlier studies ${ }^{[16]}$ have looked at the prevalence of nicotine use disorder in other psychiatric disorder in other psychiatric disorder without actually making a cause of effect relationship.

Common psychiatric disorders that are associated with nicotine use disorders are depression, ${ }^{[11,}{ }^{12]}$ anxiety, ${ }^{[13]}$ schizophrenia, ${ }^{[14]}$ ADHD, ${ }^{[60]}$ and other substance use disorders. ${ }^{[60]}$ In our study $68 \%$ had psychiatric morbidity which included depression, anxiety, alcohol dependence, mixed anxiety depression and schizophrenia.

An association seems to be exist between depression and cigarette smoking in that depressed individuals are more likely to smoke cigarette and are less successful in attempts at smoking cessation compared to non depressed individuals. ${ }^{[76]}$ In clinical samples of patients with major depression, and in a population based sample with clinically significant depressive symptoms, smoking prevalence ranges from $40-60 \%$. In our present study, $24 \%$ of the cases had Major Depressive Disorder which was in accordance with a study by Perez - stable and colleagues ${ }^{[31]}$ who reported that $21.9 \%$ of smokers had Depression in clinical sample of smokers. However population based studies ${ }^{[29]}$ have found a higher prevalence of 37-39\% depression among current smokers. In the present study also if depression and mixed anxiety depression are combined a similar high prevalence of $34 \%$ will be obtained. Overall the depression seems to be highly prevalent in both smoking as well as smokeless tobacco users. Severity of depression correlated with severity of dependence in our study.

In comparison with the research on smoking and depression, considerably less research has been carried out on the nature of the relationship between tobacco use and anxiety. It is found that anxious persons use tobacco as a means of selfmedication of anxiety symptoms.Or to avoid increased anxiety symptoms upon nicotine withdrawal. ${ }^{[52]}$ In the present study cases had higher rates of anxiety disorder [18\%] , in comparison with controls [4\%]. This is consistent with previous research ${ }^{[13,28]}$ as the usual prevalence range of $19.2 \%$ - 56\% reported earlier. ${ }^{[39]}$ similarly Farrell et al ${ }^{[16]}$ also reported $10.2 \%$ of nicotine dependents had mixed anxiety depressive disorder which is in consistent with the present study [10\%] Persons with anxiety may also find it more difficult to give up smoking.

Cases with more severe dependence had high scores on HDRS and HARS indicating more severe depressive and anxiety disorders in them. This could be in keeping with the self-medication hypothesis ${ }^{[34]}$ wherein patients with depression and anxiety use nicotine to reduce their symptoms. On the other hand it could also suggest a causal relationship of depression and anxiety with severe nicotine dependence.

Great involvement with any one substance increased the risk of other substance use. ${ }^{[9]}$ Over $75 \%$ of alcohol and drug dependents persons smoke cigarettes. ${ }^{[28]}$ smokers were significantly more likely than non-smokers to satisfy criteria for alcohol, and other drug use disorders. ${ }^{[13]}$ In the present study the $14 \%$ of ST users were dependent on alcohol. Which is much less than other studies, since the higher rates was primarily due to other substances like cocaine, $\left.{ }^{[77,}, 78\right]$ cannabis and opioids ${ }^{[78]}$ apart from nicotine dependence among the alcohol dependents patients.

Substance use is conceptualized as a maladaptive form of coping. ${ }^{[63]}$ Therefore it is likely that patients with nicotine dependence have more maladaptive coping compared to 
controls. However in the present study no significant difference was found on most coping subscales expect that Religion / Faith was used significantly less frequently by cases. This indicates that higher belief in Religion / Faith could be protective factor against substance use in our culture. In the present study cases used problem solving, Distraction positive, Acceptance / Redefinition, social support less frequently and maladaptive ways of coping like Distraction negative and Blame / Denial more frequently. However these were not significantly different from controls. Previous studies ${ }^{[7,}{ }^{80]}$ have found worse coping in more severely dependent cases. However in this study no such association was found.

Examination of the number of coping skills employed provides information about performance, but those not permit judgments regarding the adequacy or skillfulness of coping. ${ }^{[79,80]}$ Further complicating measurement issues, coping may be particularly difficult to assess. Absence of any significant difference in coping between cases and controls raises doubts about the necessity and effectiveness of coping skills training in the treatment of substance use disorders.

Overall, the literature suggests coping skills are important although the several parameters surrounding coping skills have yet to be thoroughly investigated. Questions remain regarding appropriate methods for effectively measuring skill performance, whether skills training are necessary, whether certain populations may be more in need of skills training than others, and why coping skill failures occur.

\section{Conclusion}

The more severe the nicotine dependence was, the greater was the severity of anxiety and depression. However, the different coping skills used were similar between smokeless tobacco users and non-users and controls expect for higher use of Religion/ Faith seemed protective against smokeless tobacco use.

It is therefore useful to screen for psychiatric disorders among smokeless tobacco users as this has treatment implications. Since Dental professionals are first to come in contact with people using chewing tobacco there is a need to sensitize the Dental professionals regarding nicotine dependence, assessment of psychiatric morbidity and appropriate psychiatric referral services.

Future research is needed to address the issues of comorbidity, in lager samples and in population based samples especially in the Indian context where no studies have dealt with the smokeless tobacco users.

\section{References}

1. Brady K T , Randall C L. Gender differences in substance use disorders. Psychiatr Clin N Am. 1999; 22; 241-252.

2. Dierker L C, Avenevoli S, Stoler M, Merikangas K R. Smoking and depression: An examination of Mechanisms of comorbidity. Am J Psychiatry. 2002; 159: 947-953.

3. Breslau N, Kilbey M, Andreski P. Nicotine Dependence. Major Depression and Anxiety in young adults. Arch Gen Psychiatry 1991; 48:1069-1074.

4. Lybrand J, Caroff S. Management of schizophrenia with substance use disorders. PsychiatrClin N Am 2009; 32: 821-833.

5. Kaminer Y. Addictive Disorders in Adolescents. PsychiatrClin N Am. 1999;22:275-252.

6. Farrell et al. Nicotine, alcohol and drug dependence and psychiatric comorbidity: Results of a national household survey. BJP 2001;179:432-437.

7. Chadda R.K and Sengupta S.N. Tobacco Use by Indian Adolescents. Tobacco Induced Diseases. 2002; $1: 42-56$.

8. AshishAggarwal, Manish Jain, Manjeet Singh Bhatia. Pharmacotherapy for smokeless tobacco use; A Review. Delhi Psychiatry Journal 2008;11:[2]:162-173.

9. Soni Preeti, Raut D.K. Prevalence and pattern of Tobacco Consumption in India. International Research Journal of Social Sciences. 2012;1[4];36-43.

10. Foulds J, Ramstrom L, Burke M, \& Fagerstrom K. Effect of smokeless tobacco [snus] on smoking and public health in Sweden. Tobacco Control. 2003; 12, 349-359.

Copyright: () the author(s), 2019. It is an open-access article distributed under the terms of the Creative Commons Attribution License (CC BY 4.0), which permits authors to retain ownership of the copyright for their content, and allow anyone to download, reuse, reprint, modify, distribute and/or copy the content as long as the original authors and source are cited.

How to cite this article: N Vijayraj. Relationship between Smokeless Tobacco Dependence and Psychiatric Disorders. Acad. J Med. 2019;2(2):36-41.

DOI: dx.doi.org/10.21276/ajm.2019.2.2.11

Source of Support: Nil, Conflict of Interest: None declared. 